\title{
奥运期间北京地区卫星监测 $\mathrm{NO}_{2}$ 柱浓度的变化
}

余环 ${ }^{(2)}$, 王普才 ${ }^{(\mathbb{*} *}$, 宗雪梅 ${ }^{\circledR}$, 李昕 ${ }^{(3)}$, 吕达仁 ${ }^{\circledR}$

(1) 中国科学院大气物理研究所中层大气和全球环境探测实验室, 北京 100029;

(2) 中国科学院研究生院, 北京 100049;

(3) 北京市环境保护局, 北京 100044

* 联系人, E-mail:pcwang@mail.iap.ac.cn

2008-12-29 收稿, 2009-01-15 接受

北京市科学技术委员会大气污染控制专项基金(批准号: Z005190042791)、国家自然科学基金(批准号: 40875084)和国家重点基础研究发展计 划(编号: 2006CB403702)资助项目

摘要 利用美国 Aura 卫星装载的 OMI 仪器观测反演得到的对流层 $\mathrm{NO}_{2}$ 柱浓度资料, 通过与 北京近年(2005 2007 年)同期及其与周边城市天津和唐山的综合比较, 评估了北京奥运空 气质量保障措施的实施效果. 奥运会期间华北地区对流层 $\mathrm{NO}_{2}$ 柱浓度分布图像资料清楚地 说明了北京市实施奥运空气质量保障方案的显著效果, 北京市 $\mathrm{NO}_{2}$ 柱浓度明显低于周边城 市天津和唐山, 而 2005 2007 年同期三地具有大致相同的 $\mathrm{NO}_{2}$ 柱浓度. 进一步定量评估给 出了保障措施关键时期 2008 年 7 8 月北京地区对流层 $\mathrm{NO}_{2}$ 柱浓度下降了约 40\%的结果.

关键词

北京奥运会

空气质量保障措施

效果评估

OMI

$\mathrm{NO}_{2}$
$\mathrm{NO}_{2}$ 是对流层大气中的一种重要痕量气体, 它和 $\mathrm{NO}\left(\right.$ 统称为 $\mathrm{NO}_{x}$ ) 在对流层化学中起重要作用. $\mathrm{NO}_{x}$ 参 与光化学催化臭氧产生, 导致光化学烟雾和对流层 臭氧的增加, 由 $\mathrm{NO}_{x}$ 生成的硝酸会与其他物质一起 形成酸雨, 对动植物和人类产生很大的危害.

$\mathrm{NO}_{x}$ 源主要来自化石燃料燃烧、土壤排放、生物 体燃烧和闪电 ${ }^{[1]}$, 人为排放源有很大的贡献 ${ }^{[2,3]}$, 在人 为源中, 主要来自交通运输工具的尾气排放, 其次是 电厂和工业源 ${ }^{[1]}$. 在非取暖期, 机动车尾气排放对北 京地区对流层 $\mathrm{NO}_{2}$ 浓度贡献可能高达 $70 \%{ }^{[4]}$. 中国作 为一个迅速发展的发展中国家, 车辆保有量激增, 因 此 $\mathrm{NO}_{x}$ 的排放也迅速增长, 增速远远高于其他国家 [2,5 7].

1990 年代以来, 卫星环境遥感应用领域越来越 广, 几乎覆盖了环境保护的各个方面. 与地面观测相 比, 卫星观测具有覆盖范围广、实时、连续、分辨率 高的优势, 可以获得常规观测手段无法获得的重要 参数, 观测大气中微量气体的长期变化趋势. 对全球 对流层 $\mathrm{NO}_{2}$ 的分布观测从 1996 年就开始通过不同卫 星上的传感器测量得到了一系列的结果 ${ }^{[4,8,9]}$.

北京作为全国政治、经济和文化的中心，社会发
展迅速, 已经成为世界上快速发展的大都市之一, 然 而, 城市发展所伴随是建设规模的不断扩大、人口密 度的不断增加、机动车数量的快速增长等因素, 导致 了污染物的大量排放, 造成了较为严重的大气环境 污染. 北京市在申办 2008 年奥运会时提出了“绿色奥 运、科技奥运和人文奥运”三大主题, “绿色奥运” 摆 在第一位. 为切实履行申办奥运会时的环保承诺, 进 一步改善空气质量, 成功举办一届有特色、高水平的 奥运会，在 2008 年北京奥运会、残奥会期间(7 月 20 日至 9 月 20 日)实施了加强机动车管理、严格控制施 工重点工序、重点污染企业减排等 6 大措施, 确保良 好的空气质量. 其中对北京市机动车和外省区市进 京车辆的交通管理措施从 7 月 1 日开始实施. 截止到 北京奥运会举行时, 按照北京市环境保护局提供的 官方数据, 北京市机动车保有量已经达到 340 万辆. 由于奥运交通管制措施和北京市空气质量保障措施 的实施, 在奥运会举行期间, 约有 $60 \%$, 即约 200 万 辆车辆停驶.

北京市奥运空气质量保障措施是分几个阶段逐 步实施的. 从 6 月 23 日开始, 政府机关和企事业单位 机动车自行停驶 50\%, 7 月 1 日以后, 增加到 70\%. 从 
7 月 1 日开始, 高排放黄标车禁行, 外地货运车辆禁 止驶入北京界内, 绕行河北. 从 7 月 20 日起, 实施机 动车单双号分日行驶. 7 月 1 日以前, 北京及周边地 区的高排放工厂被要求达标排放, 部分企业被要求 减产、停产, 以减少污染物排放. 所有奥运空气质量 保障措施到 9 月 20 日残奥会结束后停止. 根据北京 市环境保护局的监测结果及其委托北京工业大学和 中国环境科学研究院所做的调查结果: 7 月 1 日前, 北京市属高排放工厂基本上按北京市政府要求做到 了达标排放, 而周边地区当时还没有做到达标排放, 是在临近奥运的一段时间内逐步实现达标排放的.

地球观测系统(EOS)的 Aura 卫星上的臭氧监测 仪(OMI)观测资料是获得 $\mathrm{NO}_{2}$ 柱浓度区域分布的重要 资料. 这里利用 OMI 资料，通过北京奥运期间与 2005 2007 年近年同期资料以及相邻城市天津与唐 山的比较, 分析了北京市空气质量发生的变化及其 与周边城市的差别, 以评估奥运空气质量保障措施 对于北京市空气质量改善的效果.

\section{$1 \mathrm{OMI}$ 卫星仪器与 $\mathrm{NO}_{2}$ 柱浓度反演方法}

OMI是一台由荷兰皇家气象学会和芬兰气象学 会共同研制, 用于天底扫描的紫外-可见光波段成像 光谱仪, 可以观测直接太阳辐射和地球反射的太阳 辐射, 搭载在NASA地球观测系统系列卫星的Aura卫 星上, 2004 年 7 月 15 日发射升空. 这是一颗太阳同步 轨道的极轨卫星, 轨道高度约 $705 \mathrm{~km}$, 过境时间一 般在当地时 $13: 40 \sim 13: 50$. 观测光谱范围 $270 \sim 500$ $\mathrm{nm}$, 扫描宽度约为 $2600 \mathrm{~km}$, 每天完成一次全球扫描. OMI的空间分辨率在天底位置约为 $24 \mathrm{~km} \times 13 \mathrm{~km}$, 到 扫描边缘分辨率降低很多, 达到 $128 \mathrm{~km} \times 13 \mathrm{~km}^{[10,11]}$.

$\mathrm{OMI}$ 仪器对 $\mathrm{NO}_{2}$ 柱浓度的近实时反演算法是荷 兰皇家气象研究所(KNMI)发展的以反演-同化-模式 (RAM)方法为基础的算法 ${ }^{[10]}$. 斜柱浓度是用观测的 直接太阳辐射光谱和地球反射光谱进行光谱拟合, 即差分光学吸收方法(DOAS)得到的, 拟合波长取 (405 nm, $465 \mathrm{~nm})$, 考虑了 $\mathrm{O}_{3}$ 和旋转拉曼散射造成的 Ring效应, 采用的是非线性拟合. 平流层的 $\mathrm{NO}_{2}$ 柱浓 度和平流层 $\mathrm{NO}_{2}$ 浓度垂直分布是利用ECMWF预报的 气象场和卫星观测的 $\mathrm{NO}_{2}$ 柱浓度输入化学传输模式 TM4 得到的. 对流层空气质量因子(AMF)是通过把 模式输出的 $\mathrm{NO}_{2}$ 的廓线以及云量、云顶高度、地表反 照率、观测几何角度输入大气辐射传输模式计算出来
的. 与NASA提供标准的 $\mathrm{NO}_{2}$ 算法 ${ }^{[12]}$ 相比, 它具有处 理数据快 (从卫星数据观测, 经过数据传输, 数据处 理, 到生成产品, 画图约需要 3 小时 40 分钟, 而标准 算法需要 $1 \mathrm{~d}$ ), 反演误差较小的特点 ${ }^{[10]}$.

单个 $\mathrm{NO}_{2}$ 柱浓度中的反演中, 斜柱浓度的反演误 差为 $\pm 0.5 \times 10^{15} \sim \pm 1.5 \times 10^{15}$ 分子 $\cdot \mathrm{cm}^{-2}, \mathrm{AMF}$ 的计算的 不确定性在 $10 \% \sim 40 \% \frac{[10,13]}{}$.

$\mathrm{OMI}$ 仪器观测的对流层 $\mathrm{NO}_{2}$ 柱浓度已经被广泛 应用于监测全球范围内不同地区的 $\mathrm{NO}_{2}$ 柱浓度的年 变化趋势、全球分布特征、重要大气环境事件的监测 及影响评估 ${ }^{[4,6,7]}$.

\section{2 奥运期间北京地区 $\mathrm{NO}_{2}$ 柱浓度相对于近 年同期和周边地区的变化}

为了定量评估北京奥运期间所采取的系列空气 质量保障措施对削减氮氧化物排放的效果, 首先获 得了从 OMI 观测数据反演的华北地区 2005 2007 年 夏季(6 8 月) $\mathrm{NO}_{2}$ 柱浓度的平均分布, 如图 1. 然后 把 2008 年奥运期间及其之前的北京 $\mathrm{NO}_{2}$ 柱浓度与 2005 2007 年同期进行了比较, 并且还与类似工业 区域天津和唐山的情况做了比较, 得出了奥运期间 北京 $\mathrm{NO}_{2}$ 柱浓度相对于近年同期及其污染情况类似 的天津和唐山发生的变化或差别.

图 1 给出了从 $\mathrm{OMI}$ 数据反演并经过统计计算得 到的 2005 2007 年夏季(6 8 月) $\mathrm{NO}_{2}$ 柱浓度的平均 分布图. 有效云量大于 $50 \%$ 的数据没有进入统计样 本, 是为了保证好的数据质量. 有效样本数占统计区 间日数的 $40 \%$ 左右. 图中一个显著特点是存在以北 京、天津、唐山为中心的 3 个高 $\mathrm{NO}_{2}$ 浓度分布区, 分 布面积大致相当. 这 3 个区域都是人口较多或者工业 比较发达的区域, 其他区域浓度较小, 这主要是由于 $\mathrm{NO}_{2}$ 的寿命比较短, 特别是夏季, 其寿命只有几个小 时, 使得污染物不可能长距离输送. 选取以 $\left(116.38^{\circ} \mathrm{E}\right.$, $\left.39.94^{\circ} \mathrm{N}\right),\left(117.38^{\circ} \mathrm{E}, 39.06^{\circ} \mathrm{N}\right),\left(118.38^{\circ} \mathrm{E}, 39.81^{\circ} \mathrm{N}\right)$ 为 中心, $0.75^{\circ}($ 经度 $) \times 0.5^{\circ}$ (纬度)范围的区域代表北京、 天津、唐山 3 个污染区域, 来分析污染区域的 $\mathrm{NO}_{2}$ 浓度变化. 对北京来说, 这个区域大致相当于六环路 围成的区域, 约 $2000 \mathrm{~km}^{2}$. 这个分辨率既能够很好表 现 $\mathrm{NO}_{2}$ 的高浓度区域, 又包含足够的卫星观测像元, 可以减少单个像元的反演产生的误差. 


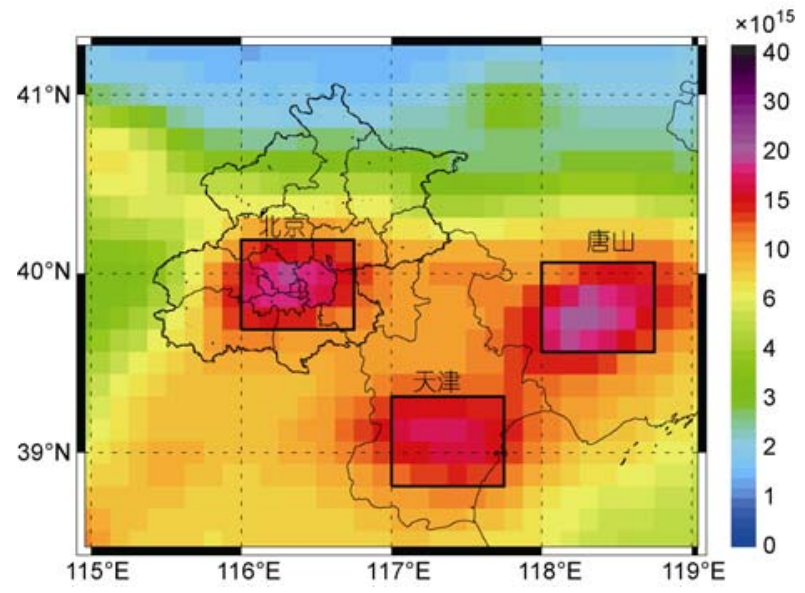

图 $12005 \sim 2007$ 年夏季(6 8 月)京津唐地区 $\mathrm{NO}_{2}$ 垂直柱浓度平均分布

单位是分子 $\cdot \mathrm{cm}^{-2}, \mathrm{OMI}$ 的像素分辨率是 $0.125^{\circ} \times 0.125^{\circ}$. 图中黑框 标示的 3 个区域是以 $\left(116.38^{\circ} \mathrm{E}, 39.94^{\circ} \mathrm{N}\right),\left(117.38^{\circ} \mathrm{E}, 39.06^{\circ} \mathrm{N}\right)$, $\left(118.38^{\circ} \mathrm{E}, 39.81^{\circ} \mathrm{N}\right)$ 为中心, $0.75^{\circ} \times 0.5^{\circ}$ 范围的区域, 分别用来代表 北京、天津、唐山 3 个污染区域. 这 3 个区域的 $\mathrm{NO}_{2}$ 污染物平均 柱浓度大致相当, 约为 $15 \times 10^{15}$ 分子 $\cdot \mathrm{cm}^{-2}$

对于北京奥运会期间及其前后的 $\mathrm{NO}_{2}$ 浓度分布 及其变化, 我们密切关注, 尽最大可能获得了相关数 据, 以评估奥运空气质量保障措施的实施效果. 图 2 显示的是北京地区 2008 年 $6 \sim 8$ 月 $\mathrm{NO}_{2}$ 浓度的逐日 变化. 可以看出, 6 月北京 $\mathrm{NO}_{2}$ 的柱浓度比较大, 其变 化也比较大, 经常有 $20 \times 10^{15}$ 分子 $\cdot \mathrm{cm}^{-2}$ 的高值, 特别 是 6 月 5 日和 12 日柱浓度分别高达 $47 \times 10^{15}$ 和 $36 \times 10^{15}$ 分子 $\cdot \mathrm{cm}^{-2} .6$ 月下旬, 由于连日的阴雨天气, 数据基 本缺失. 7 月以后, 北京的 $\mathrm{NO}_{2}$ 柱浓度一直维持较低
的浓度，一般都在 $5 \times 10^{15} \sim 15 \times 10^{15}$ 分子 $\cdot \mathrm{cm}^{-2}$ 范围内 变化. 相比北京, 临近的天津和唐山地区 $\mathrm{NO}_{2}$ 浓度一 直变化较大, 7 月以后, 天津和唐山的 $\mathrm{NO}_{2}$ 柱浓度一 般都高于北京的值, 而 6 月, 北京的 $\mathrm{NO}_{2}$ 柱浓度经常 高于天津和唐山的值. 夏季 $\mathrm{NO}_{2}$ 的生命时间比较短, 一般只有数小时, 不可能长距离输送, 所以 $\mathrm{NO}_{2}$ 的浓 度分布主要是与排放源和天气系统有关. 由于北京 市政府对机动车采取了限行措施以及对北京及周边 的高排放工厂实行了停产、限产、达标排放等控制措 施, 使得 7 月以来的北京地区 $\mathrm{NO}_{2}$ 柱浓度远远低于临 近的天津和唐山地区, 同时也低于北京 6 月的值, 可以认为这是奥运会空气质量保障措施实施带来的 效果.

为了尽可能剔除天气系统的影响, 并与 2005 2007 年同期的数据进行比较, 图 3 把观测的 $\mathrm{NO}_{2}$ 柱 浓度做了 $10 \mathrm{~d}$ (旬)平均. 6 月(除了下旬)的 $\mathrm{NO}_{2}$ 柱浓度 北京要高于天津、唐山, 而 7 月主要空气质量保障措 施实施以后, 北京的 $\mathrm{NO}_{2}$ 柱浓度就开始走低, 明显低 于天津和唐山, 差别在 $5 \times 10^{15} \sim 10 \times 10^{15}$ 分子 $\cdot \mathrm{cm}^{-2}$ 之 间. 2005 2007 年同期并不完全相同，6 月唐山的浓 度要略高于北京和天津, 7 月以后 3 个区域浓度相差 不大, 唐山浓度略高, 说明在不采取污染控制措施的 时期, 北京与天津、唐山污染情形相似, 污染程度相 当. 图中显示的 7 月初开始出现的 $\mathrm{NO}_{2}$ 浓度的大幅度 下降，与 7 月 1 日实施的黄标车禁行的时间一致. 这 说明黄标车禁行对于大幅度削减污染物的排放非常 有效. 目前北京市在用黄标车数目有 30 多万辆,

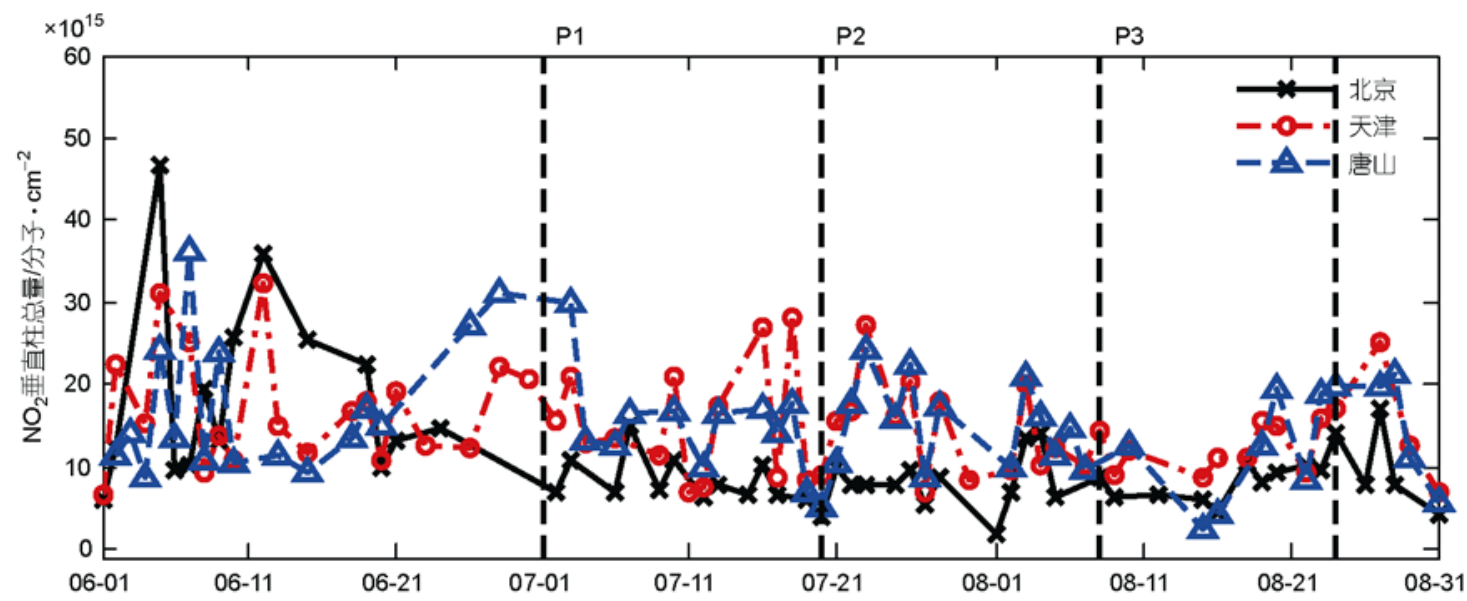

图 2 北京地区 2008 年 $6 \sim 8$ 月 $\mathrm{NO}_{2}$ 柱浓度的逐日变化

黑色叉形符号表示北京的浓度, 红色圆形符号表示天津的浓度, 蓝色三角形符号表示唐山的浓度. P1, 7 月 1 日, 开始黄标车禁行; P2, 7 月 20 日, 开始机动车单双号分日行驶; P3, 8 月 8 24日, 奥运会期间. 全部奥运空气质量保障措施到 9 月 20 日残奥会结束后停止 

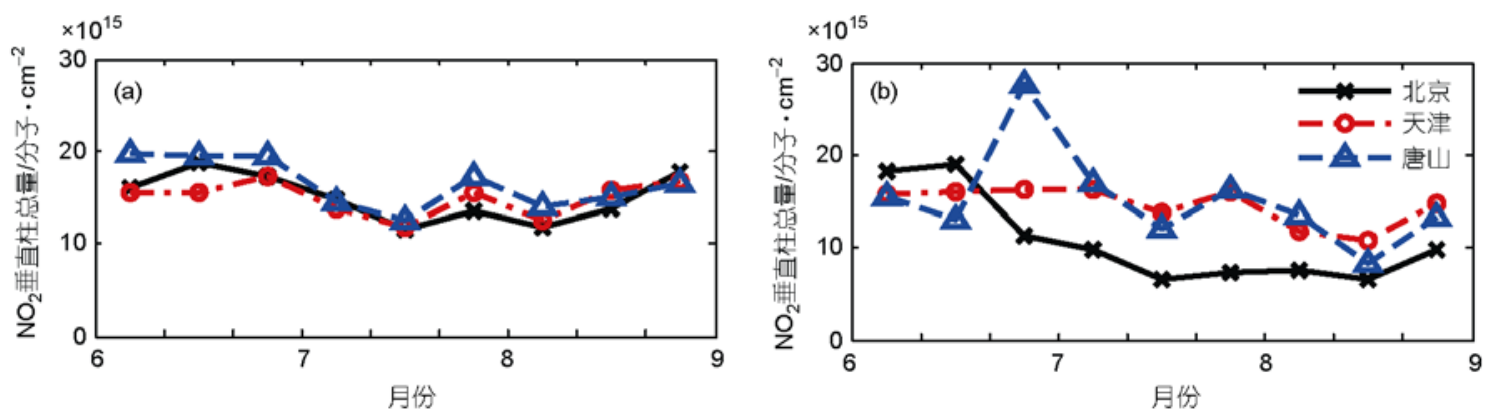

图 3

(a) 2008 年 $6 \sim 8$ 月北京地区 $10 \mathrm{~d}$ 平均的 $\mathrm{NO}_{2}$ 柱浓度变化图; (b) 2005 2007 年同期 $\mathrm{NO}_{2}$ 的平均浓度变化. 黑色叉形符号表示北京的 浓度, 红色圆形符号表示天津的浓度, 蓝色三角形符号表示唐山的浓度

由于一辆黄标车的污染物排放是达标车排放的若干 倍, 它们在所有机动车排放总量中的分担率很大, 但 准确的分担率还需要专门研究才能给出. 而比较 7 月 $1 \sim 20$ 日与 7 月 20 日 8 月 31 日两个时期北京地区 的 $\mathrm{NO}_{2}$ 浓度变化，后一时期小于前一时期. 说明低排 放机动车的限行不如高排放黄标车禁行有效.

图 4(a)给出了奥运期间及其前后北京、天津、唐 山 $7 \sim 8$ 月 $\mathrm{NO}_{2}$ 柱浓度的平均分布状况，与 2005 2007 年同期的情况(图 1)比较, 可以直观地看出奥运期间 北京与周边大城市的显著差别, 而在近年同期这 3 个 城市污染状况具有很好的相似性. 2008 年 $7 \sim 8$ 月, 北京城区的高值要明显低于天津、唐山的高值, 北京 城区 $\mathrm{NO}_{2}$ 柱浓度都在 $10 \times 10^{15}$ 分子 $\cdot \mathrm{cm}^{-2}$ 以下，而天 津、唐山市区值在 $15 \times 10^{15} \sim 20 \times 10^{15}$ 分子 $\cdot \mathrm{cm}^{-2}$ 之间, 而 $2005 \sim 2007$ 年同期, 北京、天津、唐山市区浓度 都在 $15 \times 10^{15}$ 分子 $\cdot \mathrm{cm}^{-2}$ 以上. 整体上, 无论是天津还 是唐山, 2008 年的 $\mathrm{NO}_{2}$ 柱浓度都要低于 2005 2007
年平均浓度，这说明周边省份一些高排放企业的停 产、限产等奥运空气质量保障措施对降低大气污染物 的浓度也产生了一定的效果，事实上，天津还在奥运 期间在环路以内实施了单双号分日行驶的交通管制 措施. 只是天津、唐山的减排效果远没有北京那样明 显, 当然那里的空气质量保障措施也远没有北京那 样力度大、时间长、范围广、执行严.

3 奥运期间空气质量保障措施降低 $\mathrm{NO}_{2}$ 柱 浓度的定量效果评估

表 1 给出了 2008 年和 $2005 \sim 2007$ 年 6, $7 \sim 8$ 月 北京、天津和唐山的平均 $\mathrm{NO}_{2}$ 柱浓度. 可以看出, 由 于北京、天津和唐山三地的大气污染形势的相似性, 没有采取空气污染控制措施的时段, 包括 2005 2007 年 7 8 月和 2008 年 6 月, 北京与天津和唐山的 $\mathrm{NO}_{2}$ 柱浓度差别很小，在 $16.2 \times 10^{15} \sim 18.7 \times 10^{15}$ 分 子 $\cdot \mathrm{cm}^{-2}$ 之间, 尤其是北京和天津, $\mathrm{NO}_{2}$ 柱浓度平均
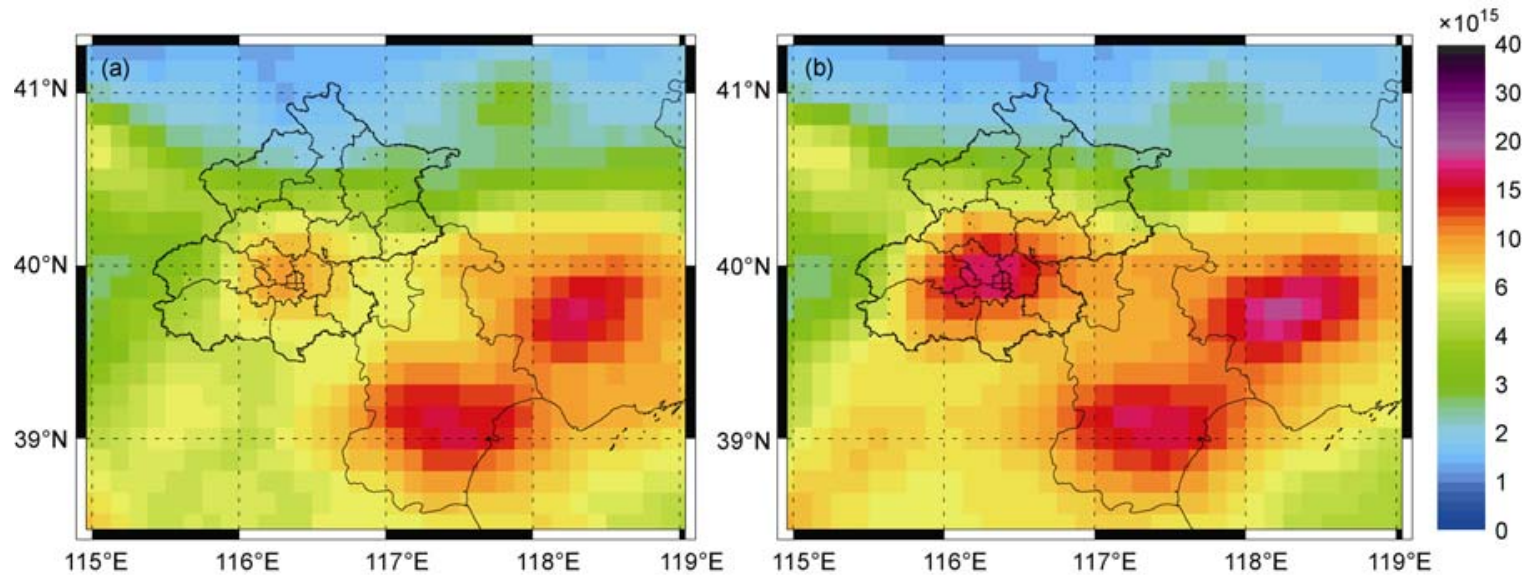

图 4 北京地区 7 8 月 $\mathrm{NO}_{2}$ 柱浓度平均分布图

(a) 2008 年平均; (b) $2005 \sim 2007$ 年平均, 单位为分子 $\cdot \mathrm{cm}^{-2}$ 
表 1 北京地区夏季对流层 $\mathrm{NO}_{2}$ 浓度(单位: $10^{15}$ 分子 $\cdot \mathrm{cm}^{-2}$ )

\begin{tabular}{clcccc}
\hline & \multicolumn{2}{c}{2008 年 } & & \multicolumn{2}{c}{$2005 \sim 2007$ 年 } \\
\cline { 2 - 3 } \cline { 5 - 5 } 月 & $7 \sim 8$ 月 & & 6 月 & $7 \sim 8$ 月 \\
\hline 北京 & 16.2 & 7.9 & & 17.4 & 13.9 \\
天津 & 16 & 13.8 & & 16.1 & 14.4 \\
唐山 & 18.7 & 13.4 & 19.6 & 15.0 \\
\hline
\end{tabular}

值基本一样, 而在 2008 年 7 8 月实施奥运空气质量 保障措施期间, 北京 $\mathrm{NO}_{2}$ 柱浓度降低到 $7.6 \times 10^{15}$ 分 子 $\cdot \mathrm{cm}^{-2}$, 只有 $2005 \sim 2007$ 年的一半左右, 而天津、 唐山两地变化不大, 2008 年浓度略低. 这说明奥运空 气质量保障措施的实施显著地改善了北京市奥运期 间的空气质量, 有力地保障了北京奥运会在良好的 空气质量情况下举行.

表 2 给出了 2008 年和 2005 2007 年同期, 北京、 天津、唐山 3 地 $\mathrm{NO}_{2}$ 柱浓度的比较结果. 这里做了 3 种比较. 第一, 把 2008 年 $7 \sim 8$ 月与 $2005 \sim 2007$ 年同 期比较, 北京、天津、唐山浓度都有所下降, 天津、 唐山下降幅度比较小, 只有 $4.2 \%$ 和 $10.7 \%$, 而北京高 达 43.2\%; 第二, 把 2008 年 7 8 月的浓度与同年 6 月 相比, 发现北京也有很大的降幅, 达到 $51.2 \%$, 明显高 于天津、唐山的 $13.8 \%$ 和 $28.3 \%$; 第三, 为了考察北京 奥运会空气质量保障措施实施与 $\mathrm{NO}_{2}$ 柱浓度下降的关 系, 还比较了 2005 2007 年 7 8 月和 6 月的 $\mathrm{NO}_{2}$ 柱 浓度, 发现下降幅度对于北京也仅为 $20.1 \%$, 而天津、 唐山分别为 $10.6 \%$ 和 $23.5 \%$, 降幅比 2008 年略低.

我们知道, 决定 $\mathrm{NO}_{2}$ 柱浓度的因素主要有 3 个: $\mathrm{NO}_{x}$ 的排放源, $\mathrm{NO}_{x}$ 的寿命和 $\mathrm{NO}_{x}$ 的区域输送. 根据 我们多年来对夏季的天气记录, 华北地区天气过程 的周期一般是 5 7 d, 因此我们采用了 $10 \mathrm{~d}$ 的平均浓 度, 以最大可能去除天气过程的影响, 得出 $\mathrm{NO}_{2}$ 柱浓 度与空气质量保障措施的关系. 为了得出奥运空气 质量保障措施的准确减排效果, 我们还考察了 $\mathrm{NO}_{x}$ 排放量的逐年变化率. 我们以 $1 \sim 6$ 月的 $\mathrm{NO}_{2}$ 平均浓 度来研究源排放强度的变化, 因为无论是 2005 2007 年还是 2008 年, 都是没有受到空气质量保障措施的
影响. 以 $1 \sim 6$ 月作为统计区间, 2008 年和 $2005 \sim$ 2007 年北京市的 $\mathrm{NO}_{2}$ 平均柱浓度分别为 $24.9 \times 10^{15}$ 和 $24.8 \times 10^{15}$ 分子 $\cdot \mathrm{cm}^{-2}$, 差别很小, 可以认为北京市的 平均源排放强度没有发生变化, 因此得出, 7 月以来 北京市空气质量保障方案实施以来, $\mathrm{NO}_{2}$ 柱浓度下降 了 43.2\%. 这是通过 2008 年 7 8 月和 2005 2007 年 同期比较获得的北京市 $\mathrm{NO}_{2}$ 柱浓度变化的结果, 这 个结果可以看作是由于北京市奥运空气质量保障措 施实施带来的减排效果. 而用相同的方法, 得到包括 奥运会的 2008 年 7 8 月天津、唐山分别下降了 18.1\% 和 $19.6 \%$.

另外一种评估奥运空气质量保障措施的减排效 果的方法是, 把实施保障措施的 2008 年 $7 \sim 8$ 月和没 有实施的 6 月比较, 这样不需要考虑排放源强度的逐 年变化, 只需要考虑 $\mathrm{NO}_{2}$ 季节变化的影响, 以2005 2007 年 $\mathrm{NO}_{2}$ 的月平均变化作为基准, 来计算如果不 实施奥运空气质量保障措施 2008 年 $7 \sim 8$ 月应该出现 的 $\mathrm{NO}_{2}$ 柱浓度, 计算公式如下:

$$
\begin{aligned}
& \mathrm{NO}_{2}^{*} \text { [Jul Aug.2008] }= \\
& \mathrm{NO}_{2} \text { [Jun.2008] } \frac{\mathrm{NO}_{2}[\mathrm{Jul} \sim \text { Aug.2005 2007] }}{\mathrm{NO}_{2}[\text { Jun.2005 2007] }} .
\end{aligned}
$$

然后比较实施保障措施后实际观测的 $\mathrm{NO}_{2}$ 柱浓度和 如果不实施保障措施应该出现的柱浓度, 得到北京、 天津、唐山 2008 年 7 8 月 $\mathrm{NO}_{2}$ 柱浓度分别下降了 $38.9 \%, 3.6 \%, 6.3 \%$. 后一种评估方法由于不需要考虑 排放源强度的年变化影响, 其结果应具有更高的可 信度.

\section{4 结论}

利用 $\mathrm{OMI}$ 对流层 $\mathrm{NO}_{2}$ 柱浓度数据, 通过对北京 奥运期间与近年同期数据及污染程度类似的邻近城 市天津和唐山的比较, 分析了奥运期间北京地区实 施空气质量保障方案以来 $\mathrm{NO}_{2}$ 对流层柱浓度变化和 时空分布特征, 得到以下结果.

（i ）卫星监测结果显示, 通常情况下, 在北京

表 2 北京地区夏季对流层 $\mathrm{NO}_{2}$ 浓度变化比较

\begin{tabular}{cccc}
\hline & 2008 年 7 8 & 2008 年 7 8 月 & $2005 \sim 2007$ 年 $7 \sim 8$ 月 \\
& 相对 $2005 \sim 2007$ 年 7 8 月变化 & 相对 2008 年 6 月变化 & 相对 2005 2007 年 6 月变化 \\
\hline 北京 & $-43.2 \%$ & $-51.2 \%$ & $-20.1 \%$ \\
天津 & $-4.2 \%$ & $-13.8 \%$ & $-10.6 \%$ \\
唐山 & $-10.7 \%$ & $-28.3 \%$ & $-23.5 \%$ \\
\hline
\end{tabular}


及其 $200 \mathrm{~km}$ 以内的周边地区存在 3 个 $\mathrm{NO}_{2}$ 高值区, 分别以北京市、天津市、唐山市为中心. $7 \sim 8$ 月 3 个 中心区的对流层 $\mathrm{NO}_{2}$ 柱浓度平均值大致相同, 在 $14 \times 10^{15} \sim 15 \times 10^{15}$ 分子 $\cdot \mathrm{cm}^{-2}$ 之间.

(ii ) 奥运会期间, 北京市由于实施了严格的空 气质量保障方案, 北京市的 $\mathrm{NO}_{2}$ 柱浓度明显低于周 边的天津和唐山的, 而近年同期三地具有大致相同
的 $\mathrm{NO}_{2}$ 柱浓度.

(iii) 通过 2008 年 $7 \sim 8$ 月北京对流层 $\mathrm{NO}_{2}$ 柱浓 度分别和 $2005 \sim 2007$ 年同期以及 2008 年 6 月的浓度 的比较, 在尽量去除天气过程和源强度变化的影响 之后, 采用两种评估方法得到北京市 $\mathrm{NO}_{2}$ 柱浓度分 别下降 43.2\%和 $38.9 \%$, 或者说北京奥运空气质量保 障措施的实施使北京市 $\mathrm{NO}_{2}$ 柱浓度下降了 $40 \%$ 左右.

感谢 TEMIS 网站 www.temis.nl 提供的由荷兰皇家气象研究会(KNMI)反演的 $\mathrm{OMI}$ 的 $\mathrm{NO}_{2}$ 数据, 感谢审稿专家提 出的建设性意见.

\section{参考文献}

1 Seinfeld J H, Pandis S N. Atmospheric Chemistry and Physics(From Air Pollution to Climate Change). San Francisco: A Wiley-Interscience Publication, 1998. 70

2 Beirle S, Platt U, Wenig M, et al. Weekly cycle of $\mathrm{NO}_{2}$ by GOME measurements: A signature of anthropogenic sources. Atmos Chem Phys, 2003, 3: 2225-2232

3 van der A R J, Eskes H J, Boersma K F, et al. Trends, seasonal variability and dominant $\mathrm{NO}_{x}$ source derived from a ten year record of $\mathrm{NO}_{2}$ measured from space. J Geophys Res, 2008, 113: D04302, doi: 10.1029/2007JD009021

4 Wang Y, McElroy M B, Boersma K F, et al. Traffic restrictions associated with the Sino-African summit: Reductions of $\mathrm{NO}_{x}$ detected from space. Geophys Res Lett, 2007, 34: L08814, doi: 10.1029/2007GL029326

5 Richter A, Burrows J P, Nüß H, et al. Increase in tropospheric nitrogen oxide over China observed from space. Nature, 2005, 437: 129 -132 [doi]

6 van der A R J, Peters D H M U, Eskes H, et al. Detection of the trend and seasonal variation in tropospheric $\mathrm{NO}_{2}$ over China. J Geophys Res, 2006, 111: D12317, doi: 10.1029/2005JD006594

7 张兴赢, 张鹏, 张艳, 等. 近 $10 \mathrm{a}$ 中国对流层 $\mathrm{NO}_{2}$ 的变化趋势、时空分布特征及其来源解析, 中国科学 D 辑: 地球科学, 2007, 37(10): 1409-1416

8 Richte A, Burrows J. Retrieval of Tropospheric $\mathrm{NO}_{2}$ from GOME Measurements. Adv Space Res, 2002, 29(11): 1673-1683[doi]

9 Sioris C E, Kurosu T P, Martin R V, et al. Stratospheric and tropospheric $\mathrm{NO}_{2}$ observed by SCIAMACHY: First results. Adv Space Res, 2004, 34: 780-785[ [doi]

10 Boersma K F, Eskes H J, Veefkind J P, et al. Near-real time retrieval of tropospheric $\mathrm{NO}_{2}$ from OMI. Atmos Chem Phys, 2007, 7: $2108-2118$

11 Levelt P F, van den Oord G H J, Dobber M R, et al. The Ozone Monitoring Instrument. IEEE Trans Geosci Remote Sens, 2006, 44(5): 1093-1101, doi: 10.1109/TGRS.2006.872333

12 Bucsla E J, Celarier E A, Wenig M O, et al. Algorithm for $\mathrm{NO}_{2}$ vertical column retrieval from the Ozone Monitoring Instrument. IEEE Trans Geosci Remote Sens, 2006, 44: 1245-1258, doi: 10.1109/TGRS.2005.863715

13 Boersma K F, Eskes H J, Brinksma E J. Error analysis for tropospheric $\mathrm{NO}_{2}$ retrieval from space. J Geophys Res, 2004, 109: D04311, doi: 10.1029/2003JD003962 